\title{
Have You Paid Your Rent? Servant Leadership in Correctional Education
}

\author{
ALANA J. SIMMONS and LATOSHA M. BRANCH \\ Virginia Department of Corrections, Richmond, Virginia, USA
}

Correctional educators shoulder great responsibility as they prepare their students for academic or vocational completion (Mageehon, 2006) and to accomplish that task, educators should be able to explore and employ best practices and $21^{\text {st }}$ century learning tools that are apropos for their student population. Prison classrooms also necessitate that staff familiarize themselves with security-related concepts such as identifying contraband and recognizing offender manipulation. Thus, teaching in a correctional classroom is a unique experience as educators must be equipped to separate the "student" from the "criminal". The need to incorporate a philosophy that correctional educators could use as a guide to how they interact with their students while recognizing boundaries established for the safety and security of offenders is substantial. Our goal was to uncover a leadership model that could address these needs and we agreed on servant leadership.

\section{What is Servant Leadership?}

The basis of our inquiry into the relationship between servant leadership and correctional education rests with this quote delivered by The Honorable Shirley Chisholm: "Service is the price we pay for the privilege of living on this earth." Essentially our argument is that leaders must be willing to serve in order to create change (Udani \& Lorenzo-Molo, 2013). Adult educators, specifically correctional educators, often face the challenge of establishing and maintaining an environment that is conducive to learning and personal growth while ensuring the safety of themselves and their learners. It is because of this unique environment that correctional educators have the opportunity to implement and exhibit the traits of a servant leader ${ }^{1}$.

On the surface, we perceived that there was a relationship between servant leadership and adult educa-

1 Servant leadership found its beginnings through Robert Greenleaf, who served as the Director of AT\&T's Organization and Management training program. For Greenleaf, leaders are not effective unless they are concerned about their followers. tion in general and correctional education in particular. For us, these philosophies complemented each other. Similar to adult education in the United States, servant leadership is a relatively new area of study and we were confident that the nature of adult/correctional education would be an obvious link to servant leadership and that the literature would be inundated simply because of the needs of the student population. Disappointment would be an understatement.

If you conduct an online search for "servant leadership," your search would yield results stemming from both business and religious studies. This is not surprising; after all, a businessman coined this term. From a religious viewpoint, scholars often regard a key religious figure as a servant. This is why religious communities have adopted the concept of servant leadership as much as the business world. However, as we have stated, we were surprised that it seems to have failed to impact very much on any field of education. We would contend that regardless of one's religious beliefs, or lack of beliefs, or one's involvement in business, the concept of servant leadership has much to offer correctional educators.

Through educational programming, correctional educators can bring about change in their students' lives, and in our opinion incorporating the traits of servant leadership into their classroom practices can enhance any such efforts. This is why we had expected to discover that much had been written on the role servant leadership can play in the prison classroom and its incorporation into teacher training programs. While the gap in the literature could have been a roadblock, it was instead an opportunity to prime ourselves and embark on a journey that would delve into the relationship between correctional education and servant leadership. By doing so, we believe that establishing a link between these disciplines would demonstrate how the two complement each other and it could compel teachers to pursue a deeper connection that can be realized and measured in the correctional classroom. 


\section{The 10 principles of servant leadership}

In his writings, Greenleaf (1977) discovered that there were ten characteristics that every servant leader must possess; a description follows of each of the ten characteristics along with our ideas on the relevance of each to correctional education:

1.) Empathy affords the servant leader to recognize and appreciate the diversity of the learner. Correctional educators recognize that they have non-traditional students, usually those who were not successful in the public school system. Similarly, correctional educators are aware that they teach within two cultures - the culture of the prison environment and the classroom culture itself. This knowledge and empathy allows them to appreciate the diversity within the learning environment and better combine their conflicting roles.

2.) Healing serves as a powerful force in the learning environment. It is not uncommon for offenders to receive bad news while incarcerated, such as the death of a loved one or learning that parole has been denied. Even though correctional educators are not responsible for delivering such news, they encounter the after effects in the classroom. Sometimes, it is not the message, but the delivery that can cause the most damage. The manner in which we address and communicate with our students is vitally important and knowing this can make a difference in any healing process.

3.) Listening involves the leader being able to listen to what is being said and unsaid. To do this, the leader must listen receptively while being aware of their inner voice. While this seems pretty simple, think about the times that you may have tuned out to what someone was telling you only to prepare your response. To quote modern servant leader, Stephen Covey, "Most people do not listen with the intent to understand, they listen with the intent to reply." It happens more often than you think. If we listen, process, and reflect, then we can have a greater impact on our students particularly in terms of modeling positive behavior.

4.) Persuasion deals with the ability to build consensus within an organization, rather than using a system of sanctions and rewards. This is very important in the correctional environment. We want the learner to do the right thing because it is the right thing to do, not because they will be subjected to punishment. Persuasion through consensus building leads to long-lasting change. We must begin to encourage our learners to think differently, which Greenleaf suggests is a usually a slow, deliberate and painstaking process (Black, 2010).

5.) Awareness helps us understand issues involving ethics, power and values. It allows the servant leader to view situations from a more integrated, holistic perspective. This trait is very significant in the correctional classroom because our goal is to help our students become productive citizens upon release. We need to model awareness so that they, in turn, can see it in action and learn to make better and more informed decisions.

6.) Stewardship involves the productive use of time, energy, and other resources. In correctional education, stewardship directly affects the learner. Even though the type and quantity of resources may be limited, educators are ultimately responsible for making use of the resources they have within their command to make a positive impact on the learner. As leaders in their classroom communities, educators manage their resources with the goal of serving the needs of the learner.

7.) Through the conceptualization trait of the servant leader, the adult educator is able to visualize the "whole", non-traditional learner. We, as adult/correctional educators, have a keen awareness of the history, past, and present state of the learners we serve. We use this awareness to establish goals, adjust implementation, and evaluate the effectiveness of our programs, using this foreknowledge to predict contingencies, which may lie ahead.

8.) Foresight is a characteristic closely linked to conceptualization. Greenleaf (1977) defines foresight as the ability to foresee or know the likely outcome of a situation. He explains it as "the lead that a leader has." Correctional educators possess the ability to handle daily tasks and events that come from working in a correctional setting, while simultaneously predicting future events. Foresight allows the correctional educator the ability to be more proactive in the classroom, rather than reactive.

9.) Correctional educators believe that their learners have value and are committed to the growth of each and every student under their influence. Educators take on the responsibility to do whatever is in their power to assist in the growth of the learner. As correctional educators we ask ourselves if we are assisting our students in becoming more productive, reaching their full potential, learning and growing as individuals and in return serving society for the good rather than bad.

10.) Educators know that in order for learning to take place, one must establish an environment that is conducive to learning. This is done by building community. The prison classroom community is based on the ethics of hard work, collaboration, respect and growth. This encompasses growth of the individual and growth of the members of the classroom community. We have an awareness of and respect for the diversity in our 
learning communities and utilize this diversity to our advantage by focusing on the individual strengths of each learner and how each can positively contribute to the learning process and foster the classroom community spirit.

These ten traits of servant leadership are interconnected; they are rarely executed in isolation. We believe that successful implementation by the teacher can help the learner develop the character traits of responsibility and integrity. As we know, correctional educators are not merely concerned with the academic growth of the learner, but the overall development of the learner. Modeling the traits of servant leadership is a powerful way to enhance the holistic development of our learners. We not only address their academic needs but we also strive to support their cognitive, social and psychological development while simultaneously safeguarding their physical and emotional safety. To successfully accomplish this broad and complex task we, as correctional educators, must be able to balance the affective and technical domains of our discipline. In essence, this is why we feel that servant leadership has much to offer any correctional educator.

\section{Why Servant Leadership?}

Correctional educators work with a population of learners that possess numerous and varying challenges. We believe that adult educators, specifically those in the field of correctional education, have an innate will to meet the needs of the aforementioned learner. One of the most notable challenges among our colleagues is engaging with learners who lack trust and therefore, are opposed to the traditional, authoritative style of teaching. With this in mind, the servant leadership model, like that of adult education, presents an opportunity for a shift from the teacher as the authority figure to the teacher as servant leader who facilitates the learning process.

To test if we have made the shift to servant leader, correctional educators can ask themselves the fourpart question which Greenleaf (1977) believed lay at the heart of professionalism: (1) Do those served grow as persons? (2) While being served, do those person become healthier, wiser, more autonomous and more likely themselves to become servants? (3) What is the effect of servant leadership on the least privileged of society? (4) Will they benefit or at least not be further deprived? For correctional educators, these are fundamental questions that should also lie at the heart of our efforts. We should be able to answer these questions in the affirmative. Ultimately, we see the direct result of our actions when our students complete an adult basic education (ABE) level, when they have successfully passed the $\mathrm{GED}^{2}$ or have mastered a vocational trade, and even when they reach their release date. All of these steps may be minute to a novice, but to a correctional educator, we recognize that the aggregate of these steps means that we have reached our students and have helped to make a difference. We have prepared our students to become productive citizens in their communities. It is through this lens that correctional educators can see the value in their work.

\section{Servant Leadership Teacher-Training- Moving Forward}

As evidenced from teachers' responses in a recent conference at which we presented a workshop, and that of fellow colleagues in the field, there has been increased interest in servant leadership as it relates to correctional education programs. The challenge lies in motivating correctional educators to view the philosophy of servant leadership as a value system. Effective educators, by nature, should possess the character traits of empathy and healing. Servant leadership traits, such as building community and listening, lend themselves more easily to the teacher-training process. Developing skills of awareness, foresight, and conceptualization could be addressed in planning professional development for educators. In spite of the difficulties that may arise, with strategic planning, implementation, and monitoring of targeted professional development activities, correctional educators will have the opportunity to practice and enhance these servant leadership traits.

Finally, as stated already, we content that correctional educators should possess the innate will to serve. Therefore, understanding and adhering to the principles of Greenleaf's (1977) servant leadership philosophy is advantageous in all fields of correctional education. Servant leadership provides the promise of effective and efficient correctional education programming, it can equip correctional educators with the ability to serve learners as unique individuals with diverse backgrounds and challenges within a learning environment predicated on the values of connectivity, service, hope and building community. In relation to Shirley Chisholm's quote, we can thus see that correctional educators pay their "rent" as they choose to serve.

2 The Adult Basic Education (ABE) and the General Equivalency Diploma (GED) are two commonly offered programs in the adult education field in the United States. ABE instructional classes are for adult learners who wish to improve their reading, writing, and math skills. The GED is a battery of standardized tests that focuses on the areas of RLA (Reasoning through Language Arts), social studies, science and mathematics. 


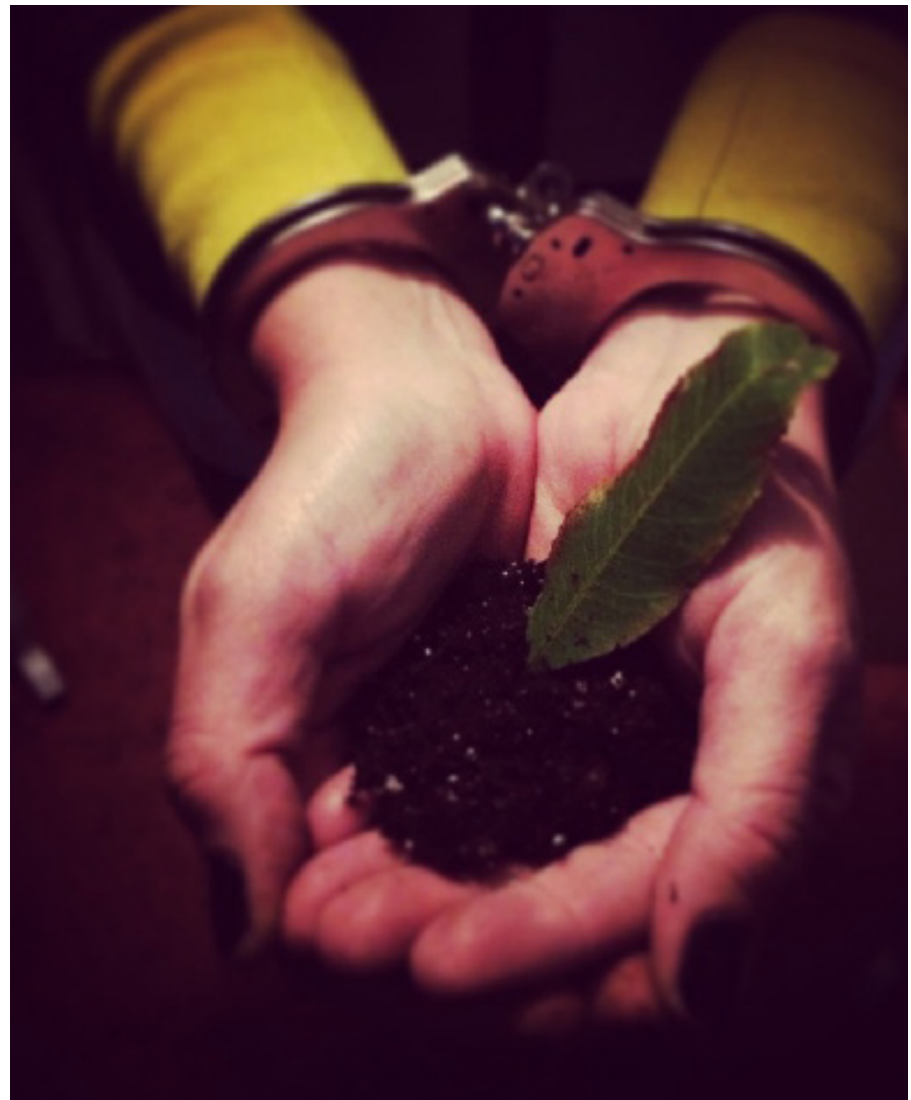

Photo by Alana Simmons

\section{References}

Black, G. L. (2010). Correlational analysis of servant leadership and school climate. Catholic Education: A Journal of Inquiry and Practice, 13(4), 437+. Retrieved from http://go.galegroup.com/ Greenleaf, R. K. (1977). Servant Leadership: A Journey Into the Nature of Legitimate Power and Greatness. New York, NY: Paulist Press.

Karanxha, Z., Agosto, V., \& Elam, D. (2011). The journey of Elam: Her servant leadership pedagogy as public intellectual. Vitae Scholasticae, 65-82. Retrieved from http://works.bepress.com/ vonzell_agosto/12

Mageehon, A. (2006). What makes a "good" teacher "good:" Women in transition from prison to community reflect. Journal of Correctional Educa tion, 57(2), 145-157. Retrieved from http://search.proquest.com.

Udani, Z., \& Lorenzo-Molo, C. (2013). When Servant Becomes Leader: The Corazon C. Aquino Success Story as a Beacon for Business Lead ers. Journal Of Business Ethics, 116(2), 373-391. doi:10.1007/s10551-012-1449-5

Dr. Alana Simmons is an Educational Tester \& Evaluator with the Virginia Department of Corrections and has more than eight years of experience in correctional education. She is also a part-time faculty member in the School of Business \& Economics at King University. Her research interests include teacher preparation for correctional educators, servant leadership (adult education \& correctional education), and women in leadership.

Latosha M. Branch is an Educational Tester \& Evaluator for the Virginia Department of Corrections-Division of Education. Latosha Branch is a graduate of Virginia Union University where she received her Bachelor's degree in Interdisciplinary Studies with a concentration in History \& Political Science. Her educational career includes working in the field of public education for 10 years in the counties of Greensville and Chesterfield prior to being employed with the VADOCDivision of Education. She is currently pursuing her Masters of Educational Leadership with the University of Virginia. She is an active advocate for equal access to quality educational opportunities for all students. She has presented at various conferences across the Commonwealth on effects of current educational policies and practices on at-risk students. 